\title{
Physical and physiological profile of Iranian world-class karate athletes
}

\author{
Hamid Arazi, Mani Izadi \\ Department of Exercise Physiology, Faculty of Sport Sciences, University of Guilan, Rasht, Iran
}

\section{Summary}

Study aim: The purpose of the present research was to determine the physical and physiological features of international level karate athletes.

Material and methods: Eleven male karate athletes who were ranked at the top of their weight categories participated in this study. All of them were evaluated for anthropometric, body composition, somatotype and bio-motor characteristics in detail. Results: The main results (mean \pm SD) were height: $181.54 \pm 4.71 \mathrm{~cm}$; sitting height: $97.27 \pm 3.03 \mathrm{~cm}$; arm span: $185.72 \pm 7.28 \mathrm{~cm}$; BMI: $25.02 \pm 3.32 \mathrm{~kg} \cdot \mathrm{m}^{-2}$; Rohrer's index: $137.68 \pm 16.72$; skelic index: $53.58 \pm 1.29$; arm span (ape) index: $1.02 \pm 0.02$; fat mass: $7.51 \pm 4.56 \mathrm{~kg}$; fat-free mass: $75.26 \pm 10.04 \mathrm{~kg}$; body fat: $8.66 \pm 3.65$; endomorphy: $2.4 \pm 0.85$; mesomorphy: 5.2 \pm 1.13 ; ectomorphy: $2.11 \pm 0.99$; $\mathrm{VO}_{2 \max }: 51.58 \pm 3.39 \mathrm{ml} \cdot \mathrm{kg}^{-1} \cdot \mathrm{min}^{-1}$; anaerobic power: $45.45 \pm 4.39 \mathrm{~W} \cdot \mathrm{kg}^{-1}$; long jump: $249.7 \pm 16.81 \mathrm{~cm}$; upper-body strength: $100.27 \pm 15.61 \mathrm{~kg}\left(1.21 \pm 0.07 \mathrm{~kg} \cdot \mathrm{kg}^{-1}\right)$; lower-body strength: $155.94 \pm 19.49 \mathrm{~kg}$ $\left(1.89 \pm 0.14 \mathrm{~kg} \cdot \mathrm{kg}^{-1}\right)$; whole-body strength: $156.97 \pm 21.38 \mathrm{~kg}\left(1.9 \pm 0.13 \mathrm{~kg} \cdot \mathrm{kg}^{-1}\right)$ and flexibility: $37.63 \pm 10.73 \mathrm{~cm}$

Conclusions: A tall stature and long arm span, low body fat, markedly high mesomorphic build, moderately high aerobic power, outstanding anaerobic power, excellent lower-body explosive power, great muscular strength and high flexibility seem to be advantageous features for karate contestants.

\section{Key words: Karate kumite - Weight divisions - Aerobic power - Anaerobic power - Body fat percentage}

\section{Introduction}

Karate is known one of the most popular martial arts all around the world. Karate consists of two main parts named kata and kumite. Kata represents a pre-arranged form of karate techniques in an exhibitive manner. Kumite means karate sparring, which involves the execution of offensive, defensive and counter-attack techniques against a rival $[22,23]$. Based on the World Karate Federation rules, an official kumite competition lasts 3 minutes for senior males and 2 minutes for senior females in elementary stages, and then lasts 1 more minute for each of them in the final stages and fight for medals [11].

Karate competition is typically defined as a high-intensity intermittent sport event, in which most of the actions are performed explosively [3, 43]. During kumite, karate athletes move in diverse directions on the karate mat and attack their rivals using punches and kicks (arm and leg techniques) [39]. Today, the changes in competition rules such as a limitation against contacts when executing techniques, transition from a single-point to a multiple-point system and an opportunity for gaining more scores using kicks have made the kumite competitions more dynamic and attractive [28], but this event has become more demanding.

It is reasonable to expect that high-level athletes will have the appropriate physique specific to the sport they are involved in. Since the beginning, a long-limbed physique has been considered suited to karate athletes. In this context, the studies on body type, structure and composition of karate athletes have reported that the dominant anthropometric characteristic is vertical development of the skeleton along with average somatotype (mesomorphic-ectomorph) [20, 26]. Karate is a sport in which athletes should be able to move their body rapidly. A higher contribution of endomorphy, therefore, can be detrimental for desired performance $[18,26]$. In sports such as karate in which the athletes compete in well-defined weight categories, an increase in body weight induced by accumulation of fat can result in unfavorable performance, indicating the vital importance of distinguishing between two major portions of the body named fat mass and fat-free mass [15]. 
Gualdi-Russo and Graziani [21] emphasized the association between somatotype and sport achievements in combative sports. However, it has remained controversial as to which is the best body type for karate athletes. Although Giampietro et al. [20] observed the meso-ectomorph somatotype for elite Italian male karate athletes, the investigation of somatotype in elite German karate athletes showed that they had a developed ectomorph component [19].

Most combative sports require a combination of biomotor attributes such as strength, aerobic fitness, power and speed, and in general, none of them is alone decisive [5]. Ravier et al. [34] found a significant difference in maximal power between national and international level karate athletes. Anaerobic power has been shown to be crucial for efficient implementation of techniques in repetitive attacks and defenses. However, although the execution of single punches and kicks requires energy supply through anaerobic metabolism and depends largely on muscular power, the consistency of optimal performance entails the aerobic metabolism. Hence, due to the frequent execution of techniques the aerobic metabolism has the greatest contribution (77.8\%) in the energy restoration during kumite [6]. Plus, the recovery between matches depends mainly on aerobic metabolism [36]. The contribution of anaerobic metabolism has also been reported as $16 \%[6,12,36]$.

Up to now, the studies that have been conducted to assess physical and physiological attributes of karate athletes have clearly demonstrated the vital importance of awareness regarding these variables. It is obvious that some of the desired characteristics among athletes are under the influence of their genetic endowment. Therefore, the results of such studies may produce sufficient information concerning genetic potential suited to favorable performance, and coaches and sport sciences experts can benefit from. Furthermore, a better understanding of the prominent characteristics of elite athletes that are in harmony with physiological needs in the top level of the sport they practice is a great step toward further success and promotion of karate. Thus, the present study aimed to assess the physical and physiological profiles of Iranian elite male karate athletes.

\section{Material and methods}

\section{Participants}

The sample included 11 senior male karate athletes (mean \pm standard deviation: $23.27 \pm 2.83$ years old, height of $181.54 \pm 4.71 \mathrm{~cm}$ and BMI of $25.02 \pm 3.32 \mathrm{~kg} \cdot \mathrm{m}^{-2}$ ) who were all members of the Iranian national karate team and were medalists in international championships (Asian and world championships). They were involved in training in the initial weeks of preparation to participate in the World Karate Championship Games. They also were highly experienced through years of karate training, and in recent years had taken part in diverse age classes and different levels of kumite competitions continuously.

This research was approved by the ethic committee on human experiments in the Faculty of Physical Education and Sport Sciences of University of Guilan. Prior to the test, a preliminary session was held with the aim of familiarization about the experiments, and written consent forms were then received. Some recommendations were made regarding regular sleep, diet and avoidance of strenuous activity within 48 hours prior to the experiments, and also no use of drugs (e.g. stimulants, diuretics and sedatives).

\section{Anthropometric measurements}

The following measurements were taken: weight (using Korona scales, to the nearest $0.1 \mathrm{~kg}$ ), the length of height, sitting height, arm span, upper arm, forearm, thigh, calf; circumferences of chest, waist, hip, arm, forearm, thigh and calf (using Lufkin W606PM flexible steel tape, to the nearest $0.5 \mathrm{~cm}$ ).

\section{Somatic indices}

The following somatic indices were calculated through recommended equations:

- BMI $\left(\mathrm{kg} \cdot \mathrm{m}^{-2}\right)=\mathrm{W} / \mathrm{H}^{2}$;

- Rohrer's index $=\mathrm{W} / \mathrm{H}^{3} \times 10$;

- Body surface area $(\mathrm{BSA})=\mathrm{SQRT}(\mathrm{H}[\mathrm{cm}] \times \mathrm{W}[\mathrm{kg}] / 3600)$;

- Skelic index $=(\mathrm{SH} / \mathrm{H}) \times 100$;

- Arm span index (ape index) $=\mathrm{AS} / \mathrm{H}$;

- Manouvrier's index $=$ leg L/SH;

- Arm length index $=\operatorname{arm~L/H}$;

- Upper extremity girth index $=$ forearm C/arm C;

- WHR = waist C/hip C;

- $\mathrm{HWR}=\mathrm{H} / \mathrm{CBRT} \mathrm{W}$;

where the abbreviations are as follows: $\mathrm{W}=$ weight, $\mathrm{H}=$ height, $\mathrm{SQRT}=$ square root, $\mathrm{SH}=$ sitting height, $\mathrm{AS}=\operatorname{arm}$ span, $\mathrm{L}=$ length, $\mathrm{C}=$ circumference, WHR $=$ waist-to-hip ratio, HWR $=$ height-to-weight ratio, $\mathrm{CBRT}=$ cube root.

\section{Body composition measurements}

Body fat percentage was calculated through 7 -site measurements of skinfold thickness (triceps, chest, midaxillary, subscapular, abdominal, suprailiac and thigh using a Slim Guide skinfold caliper). The equation of Jackson and Pollock was used to evaluate body density [25]. Then, body fat percentage was calculated using Siri's equation [37].

\section{Somatotype measurements}

Bone breadth in the humerus, femur, wrist and ankle were assessed using a Tommy 2 bone caliper (Rosscraft). Somatotypes were calculated via the Heath-Carter method and were plotted on a two-dimensional grid system (somatochart) [10]. 
All the anthropometric, somatotype and body composition measurements were taken on the right side of the body and in accordance with the ISAK guidelines [29].

\section{Physical measurements}

Strength. Bench press, squat and deadlift exercises were used to assess upper-body, lower-body and wholebody strength, respectively. Subjects were instructed to complete up to a maximum of 8 repetitions during each of 3 exercises and $1 \mathrm{RM}[\mathrm{kg}]$ was calculated via the Brzycki equation [8]:

$$
1 \mathrm{RM}=100 \times \text { load } \mathrm{rep} /(102.78-2.78 \times \mathrm{rep}) .
$$

Muscular power. The muscular power of the lowerbody was assessed by the long jump test. Additionally, the medicine ball throw test was used to evaluate upper-body muscular power. A two-kg medicine ball was used. For both tests, the subjects were allowed 3 trials and the best result was used.
Speed and agility. The 40-yard dash was considered for evaluation of speed. The time taken to cover the distance between start and end was recorded via DSI photo-finish equipment (Danesh Salar Iranian). Additionally, the $4 \times 9 \mathrm{~m}$ shuttle run test was used to determine agility.

Flexibility. The sit-and-reach test was used to evaluate the flexibility of hamstring and lower back muscles. The subjects were allowed three attempts and the highest value was used.

\section{Physiological measurements}

Aerobic power. The participants completed the one-mile run test as a measure of aerobic power. The time spent to complete one mile was entered into the following equation for relative $\mathrm{VO}_{2 \max }\left(\mathrm{ml} \cdot \mathrm{kg}^{-1} \cdot \mathrm{min}^{-1}\right)$ estimation [4]:

$$
\begin{gathered}
\mathrm{VO}_{2 \max }=108.94-(8.41 \times \text { time })+\left(0.34 \times \text { time }^{2}\right) \\
+(0.21 \times \text { age } \times \text { gender })-(0.84 \times \mathrm{BMI})
\end{gathered}
$$

where gender is coded as $1=$ male and $0=$ female and

\begin{tabular}{|c|c|c|c|c|c|}
\hline & Light weight & Middle weight & Heavy weight & \multicolumn{2}{|c|}{ Total } \\
\hline & $\mathrm{M} \pm \mathrm{SD}$ & $\mathrm{M} \pm \mathrm{SD}$ & $\mathrm{M} \pm \mathrm{SD}$ & $\mathrm{M} \pm \mathrm{SD}$ & Range \\
\hline Age [years] & $23 \pm 4.58$ & $23.33 \pm 3.05$ & $23.4 \pm 2.19$ & $23.27 \pm 2.83$ & $18-27$ \\
\hline Weight $[\mathrm{kg}]$ & $68.5 \pm 5.55$ & $77.66 \pm 0.35$ & $94.42 \pm 10.10$ & $82.78 \pm 13.55$ & $63-105.9$ \\
\hline \multicolumn{6}{|l|}{ Lengths $[\mathrm{cm}]$} \\
\hline Height & $175.33 \pm 3.51$ & $183.33 \pm 1.52$ & $184.2 \pm 2.86$ & $181.54 \pm 4.71$ & $172-188$ \\
\hline Sitting height & $94.33 \pm 2.51$ & $97.33 \pm 2.08$ & $99 \pm 2.73$ & $97.27 \pm 3.03$ & $78-89$ \\
\hline Arm span & $177 \pm 5.29$ & $189.33 \pm 7.09$ & $188.8 \pm 3.83$ & $185.72 \pm 7.28$ & $171-197$ \\
\hline Upper arm & $35.33 \pm 0.57$ & $39.33 \pm 1.15$ & $39.1 \pm 1.34$ & $38.13 \pm 2.07$ & $35-40.5$ \\
\hline Forearm & $26.5 \pm 1.32$ & $28.83 \pm 1.04$ & $29.1 \pm 1.59$ & $28.31 \pm 1.72$ & $25-31$ \\
\hline Thigh & $35.33 \pm 3.05$ & $40 \pm 1.73$ & $41.4 \pm 2.32$ & $39.36 \pm 3.42$ & $32-44.5$ \\
\hline Calf & $40.66 \pm 1.52$ & $42.66 \pm 2.08$ & $42.9 \pm 2.55$ & $42.22 \pm 2.22$ & $39-47$ \\
\hline \multicolumn{6}{|l|}{ Girths [cm] } \\
\hline Chest & $93.33 \pm 3.4$ & $98 \pm 0.86$ & $105.7 \pm 2.04$ & $100.22 \pm 5.9$ & $89.5-107.5$ \\
\hline Waist & $81.33 \pm 3.21$ & $83.5 \pm 2.78$ & $91.8 \pm 8.4$ & $86.68 \pm 7.52$ & 79-105 \\
\hline Hip & $90.16 \pm 7.14$ & $94.16 \pm 2.02$ & $101.8 \pm 4.69$ & $96.54 \pm 6.89$ & 84-106 \\
\hline Arm (relaxed) & $28.5 \pm 1$ & $29.16 \pm 1.6$ & $33 \pm 2.03$ & $30.72 \pm 2.67$ & $27.5-36$ \\
\hline Arm (flexed-tensed) & $31 \pm 2.29$ & $32.33 \pm 1.52$ & $36.8 \pm 2.28$ & $34 \pm 3.32$ & $29-40$ \\
\hline Forearm & $25.83 \pm 0.76$ & $26.16 \pm 0.76$ & $28.8 \pm 1.75$ & $27.27 \pm 1.9$ & $25-30.5$ \\
\hline Thigh & $55.5 \pm 3.04$ & $55.66 \pm 2.3$ & $63.3 \pm 3.27$ & $59.09 \pm 4.84$ & $53-67.5$ \\
\hline Calf & $36.83 \pm 3.01$ & $35.83 \pm 0.28$ & $42.32 \pm 2.97$ & $39.04 \pm 3.85$ & $34-45.5$ \\
\hline \multicolumn{6}{|l|}{ Breadths [cm] } \\
\hline Humorous & $6.8 \pm 0.1$ & $6.73 \pm 0.11$ & $6.84 \pm 0.25$ & $6.8 \pm 0.17$ & $6.6-7.2$ \\
\hline Femur & $9.9 \pm 0.3$ & $10.26 \pm 0.3$ & $10.66 \pm 0.46$ & $10.34 \pm 0.48$ & $9.6-11.2$ \\
\hline Wrist & $5.56 \pm 0.3$ & $5.53 \pm 0.23$ & $5.78 \pm 0.3$ & $5.65 \pm 0.28$ & $5.3-6.1$ \\
\hline Ankle & $7.26 \pm 0.4$ & $7.33 \pm 0.2$ & $7.5 \pm 0.39$ & $7.39 \pm 0.33$ & $6.8-8.1$ \\
\hline
\end{tabular}
one-mile time is in minutes.

Table 1. Absolute anthropometric values 
Anaerobic power. A 15-second vertical jumping test (Ergo-Jump, using DSI equipment) was used to determine anaerobic power. The subjects were asked to attempt maximal flight time and minimal landing contact during repetitive jumps. The results were reported as relative values (watts per $\mathrm{kg}$ ).

\section{Statistical analyses}

Statistical analyses were performed using IBM SPSS Statistics 20.0 software. All the variables were presented as mean and standard deviation plus range (min-max).

\section{Results}

The results were presented in two formats; in general (all the participants), and in 3 main weight categories based on target weights ( -60 and $-67 \mathrm{~kg}$ as light weight, $-75 \mathrm{~kg}$ as middle weight, and -84 and +84 as heavy weight). The results are presented in Tables 1-5 and Figure 1.

\section{Discussion}

Great sport achievements depend on various factors. In this regard, a proper understanding of prominent features of top-level athletes suited to the sport in which they compete can undeniably contribute to success. In the present research, we attempted to characterize the anthropometric, body composition, somatotype and bio-motor characteristics of international level karate athletes from Iran: an almost holistic model of genetic predispositions and functional features specific to high levels of performance in karate in terms of fieldwork investigations. Therefore, all the 11 final selected members of Iranian national karate team were assessed.

Table 2. Somatic indices

\begin{tabular}{lccccc}
\hline & Light weight & Middle weight & Heavy weight & \multicolumn{2}{c}{ Total } \\
\hline BMI $\left[\mathrm{kg} \cdot \mathrm{m}^{-2}\right]$ & $\mathrm{M} \pm \mathrm{SD}$ & $\mathrm{M} \pm \mathrm{SD}$ & $\mathrm{M} \pm \mathrm{SD}$ & $\mathrm{M} \pm \mathrm{SD}$ & Range \\
Rohrer's index & $22.25 \pm 0.91$ & $23.1 \pm 0.28$ & $27.83 \pm 2.96$ & $25.02 \pm 3.32$ & $21.3-31.97$ \\
Body Surface Area & $126.87 \pm 2.77$ & $126.06 \pm 2.59$ & $151.14 \pm 16.62$ & $137.68 \pm 16.72$ & $123.19-175.66$ \\
Scelic index & $1.82 \pm 0.09$ & $1.98 \pm 0.01$ & $2.19 \pm 0.12$ & $2.03 \pm 0.18$ & $1.73-2.32$ \\
Arm Span index & $53.80 \pm 1.09$ & $53.09 \pm 1.24$ & $53.75 \pm 1.59$ & $53.58 \pm 1.29$ & $51.63-56.04$ \\
Manouvrier's index & $1 \pm 0.01$ & $1.03 \pm 0.03$ & $1.02 \pm 0.01$ & $1.02 \pm 0.02$ & $0.99-1.06$ \\
Arm length index & $0.85 \pm 0.03$ & $0.88 \pm 0.04$ & $0.86 \pm 0.05$ & $0.86 \pm 0.04$ & $0.78-0.94$ \\
Upper extremity girth index & $0.32 \pm 0.01$ & 0.33 & 0.33 & $0.32 \pm 0.01$ & $0.31-0.35$ \\
WHR & $0.9 \pm 0.05$ & $0.89 \pm 0.02$ & $0.87 \pm 0.05$ & $0.88 \pm 0.04$ & $0.81-0.95$ \\
HWR & $60.97 \pm 0.1$ & $61.75 \pm 0.44$ & $59.17 \pm 1.68$ & $60.36 \pm 1.6$ & $56.73-62.25$ \\
Wrist/Ankle breadth & $0.76 \pm 0.02$ & $0.75 \pm 0.05$ & $0.77 \pm 0.04$ & $0.76 \pm 0.04$ & $0.71-0.83$ \\
Elbow/Knee breadth & $0.68 \pm 0.02$ & $0.65 \pm 0.03$ & $0.64 \pm 0.02$ & $0.65 \pm 0.03$ & $0.62-0.71$ \\
Biceps/Thigh girth & $0.51 \pm 0.01$ & $0.52 \pm 0.02$ & $0.52 \pm 0.02$ & $0.52 \pm 0.01$ & $0.5-0.55$ \\
Forearm/Calf girth & $0.7 \pm 0.07$ & $0.73 \pm 0.02$ & $0.68 \pm 0.04$ & $0.7 \pm 0.05$ & $0.61-0.76$ \\
\hline
\end{tabular}

Table 3. Results of somatotype assessment

\begin{tabular}{lccccc}
\hline & Light weight & Middle weight & Heavy weight & \multicolumn{2}{c}{ Total } \\
\hline & $\mathrm{M} \pm \mathrm{SD}$ & $\mathrm{M} \pm \mathrm{SD}$ & $\mathrm{M} \pm \mathrm{SD}$ & $\mathrm{M} \pm \mathrm{SD}$ & Range \\
\hline Endomorphy & $1.85 \pm 0.28$ & $2.07 \pm 0.48$ & $2.93 \pm 0.99$ & $2.4 \pm 0.85$ & $1.57-4.55$ \\
Mesomorphy & $4.89 \pm 0.59$ & $4.07 \pm 0.47$ & $6.06 \pm 0.98$ & $5.2 \pm 1.13$ & $3.54-7.27$ \\
Ectomorphy & $2.8 \pm 0.23$ & $2.86 \pm 0.22$ & $1.25 \pm 0.85$ & $2.11 \pm 0.99$ & $0.18-3.11$ \\
$\mathrm{X}$ & $0.95 \pm 0.07$ & $0.79 \pm 0.6$ & $-1.68 \pm 1.78$ & $-0.28 \pm 1.76$ & $-4.37-1.39$ \\
$\mathrm{Y}$ & $5.14 \pm 1.68$ & $3.21 \pm 0.86$ & $7.95 \pm 1.84$ & $5.89 \pm 2.55$ & $2.25-9.81$ \\
\hline
\end{tabular}




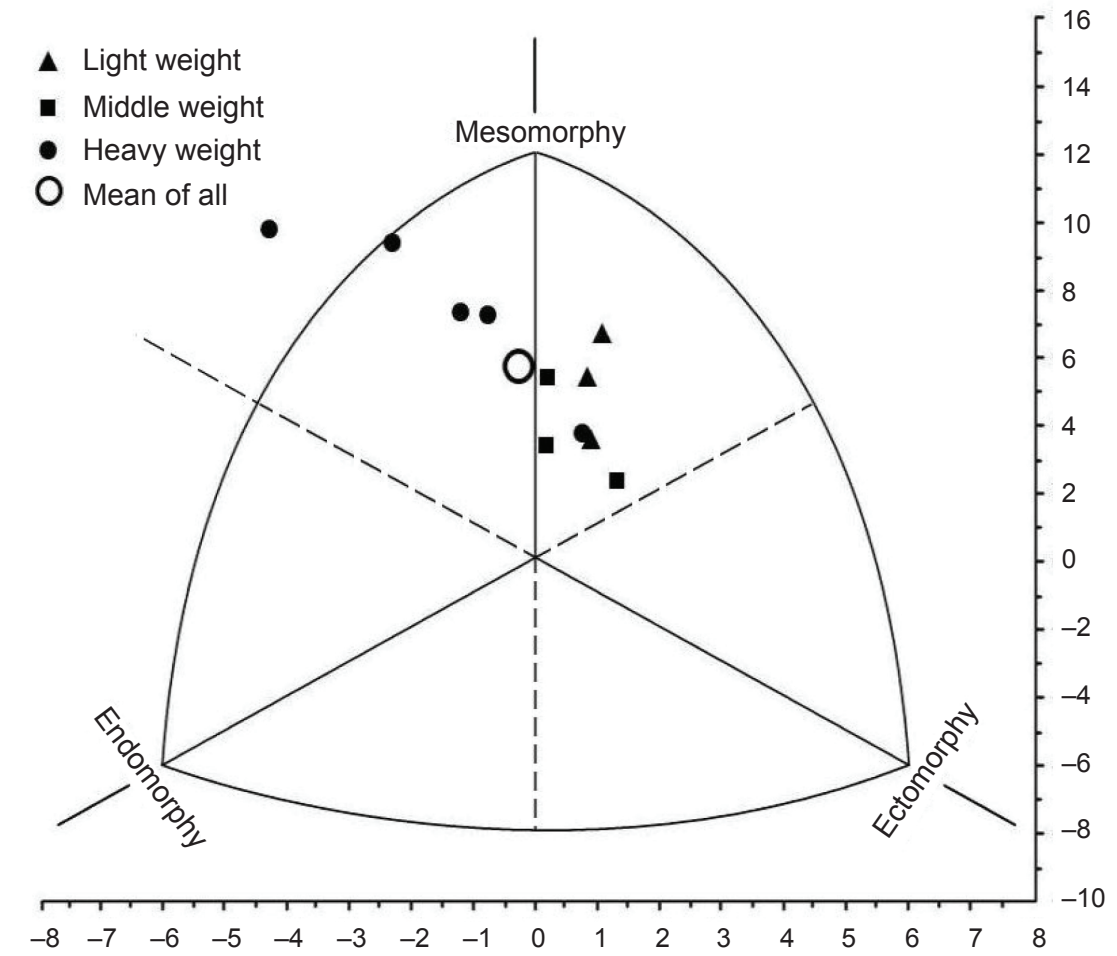

Fig. 1. Somatoplots of elite male karate athletes

Table 4. Results of body composition assessment

\begin{tabular}{|c|c|c|c|c|c|}
\hline & \multirow{2}{*}{$\begin{array}{l}\text { Light weight } \\
\mathrm{M} \pm \mathrm{SD}\end{array}$} & \multirow{2}{*}{$\frac{\text { Middle weight }}{\mathrm{M} \pm \mathrm{SD}}$} & \multirow{2}{*}{$\frac{\text { Heavy weight }}{\mathrm{M} \pm \mathrm{SD}}$} & \multicolumn{2}{|c|}{ Total } \\
\hline & & & & $\mathrm{M} \pm \mathrm{SD}$ & Range \\
\hline \multicolumn{6}{|l|}{ Skinfolds [mm] } \\
\hline Triceps & $7.33 \pm 1.52$ & $6.66 \pm 1.15$ & $10.8 \pm 3.11$ & $8.72 \pm 2.93$ & $6-14$ \\
\hline Chest & $5 \pm 1$ & $5.66 \pm 0.57$ & $8 \pm 4.58$ & $6.54 \pm 3.26$ & $4-16$ \\
\hline Midaxillary & $5 \pm 1$ & $5.66 \pm 0.57$ & $7.6 \pm 4.15$ & $6.36 \pm 2.94$ & $4-15$ \\
\hline Subscapular & 9 & $11.66 \pm 2.08$ & $14.8 \pm 6.14$ & $12.36 \pm 4.73$ & $9-25$ \\
\hline Abdominal & $10.66 \pm 3.05$ & $12 \pm 2.64$ & $15 \pm 7.38$ & $13 \pm 5.38$ & $7-27$ \\
\hline Suprailiac & $6 \pm 1$ & 6 & $10.6 \pm 5.85$ & $8.09 \pm 4.43$ & $5-21$ \\
\hline Thigh & $9 \pm 1$ & $9.33 \pm 3.05$ & $13 \pm 3.39$ & $10.9 \pm 3.26$ & $6-18$ \\
\hline \multicolumn{6}{|c|}{ Sum of skinfolds [mm] } \\
\hline Three sites & $24.66 \pm 3.51$ & $27 \pm 3.46$ & $36 \pm 15.01$ & $30.45 \pm 11.13$ & $21-61$ \\
\hline Seven sites & $52 \pm 5.19$ & $57 \pm 3.46$ & $79.8 \pm 33.04$ & $66 \pm 24.95$ & $46-136$ \\
\hline \multicolumn{6}{|l|}{ Body fat $[\%]$} \\
\hline Three sites & $6.62 \pm 1.6$ & $7.38 \pm 0.77$ & $10.08 \pm 4.47$ & $8.4 \pm 3.36$ & $4.92-17.54$ \\
\hline Seven sites & $6.54 \pm 1.36$ & $7.37 \pm 0.6$ & $10.7 \pm 4.74$ & $8.66 \pm 3.65$ & $4.98-18.71$ \\
\hline Body density & 1.08 & 1.08 & $1.07 \pm 0.01$ & 1.07 & $1.06-1.09$ \\
\hline Fat mass $[\mathrm{kg}]$ & $4.48 \pm 1.07$ & $5.72 \pm 0.46$ & $10.4 \pm 5.63$ & $7.51 \pm 4.56$ & $3.4-19.81$ \\
\hline Fat free mass $[\mathrm{kg}]$ & $64.01 \pm 5.09$ & $71.94 \pm 0.64$ & $84.01 \pm 6.32$ & $75.26 \pm 10.04$ & $58.5-91.93$ \\
\hline
\end{tabular}


Table 5. Results of bio-motor assessment

\begin{tabular}{lccccc}
\hline & Light weight & Middle weight & Heavy weight & \multicolumn{2}{c}{ Total } \\
\hline & $\mathrm{M} \pm \mathrm{SD}$ & $\mathrm{M} \pm \mathrm{SD}$ & $\mathrm{M} \pm \mathrm{SD}$ & $\mathrm{M} \pm \mathrm{SD}$ & Range \\
\hline Aerobic power $\left[\mathrm{ml} \cdot \mathrm{kg}^{-1} \cdot \mathrm{min}^{-1}\right]$ & $53.95 \pm 0.84$ & $53.85 \pm 1.4$ & $48.79 \pm 3.1$ & $51.58 \pm 3.39$ & $44.55-55.1$ \\
Anaerobic power $\left[\mathrm{W} \cdot \mathrm{kg}^{-1}\right]$ & $44.33 \pm 2.08$ & $47.66 \pm 1.52$ & $44.8 \pm 6.3$ & $45.45 \pm 4.39$ & $38-52$ \\
Long jump [m] & $2.51 \pm 0.69$ & $2.61 \pm 0.15$ & $2.41 \pm 0.19$ & $2.49 \pm 0.16$ & $2.13-2.75$ \\
Medicine ball throw [m] & $9.78 \pm 0.17$ & $10.4 \pm 2.62$ & $10.91 \pm 1.2$ & $10.46 \pm 1.48$ & $8-13.2$ \\
Speed [s] & $5.16 \pm 0.04$ & $4.9 \pm 0.05$ & $5.19 \pm 0.13$ & $5.1 \pm 0.16$ & $4.84-5.37$ \\
Agility [s] & $9.03 \pm 0.23$ & $8.34 \pm 0.2$ & $9.05 \pm 0.31$ & $8.85 \pm 0.41$ & $8.1-9.4$ \\
Flexibility [cm] & $41.66 \pm 5.03$ & $39 \pm 7.21$ & $34.4 \pm 14.92$ & $37.63 \pm 10.73$ & $8-47$ \\
\hline Absolute strength $[\mathrm{kg}]$ & & & & \\
\hline Bench press & $83.42 \pm 4.75$ & $95.55 \pm 7.71$ & $113.22 \pm 11.37$ & $100.27 \pm 15.61$ & $79.54-128.31$ \\
Half squat & $130.7 \pm 16.37$ & $160.18 \pm 1.44$ & $168.54 \pm 11.19$ & $155.94 \pm 19.49$ & $120.91-179.74$ \\
Deadlift & $127.1 \pm 4.12$ & $160.67 \pm 6.97$ & $172.67 \pm 11.06$ & $156.97 \pm 21.38$ & $124.37-182.42$ \\
\hline Relative strength $\left[\mathrm{kg} \cdot \mathrm{kg}^{-1}\right]$ & & & & & \\
\hline Bench press & $1.21 \pm 0.03$ & $1.23 \pm 0.1$ & $1.2 \pm 0.09$ & $1.21 \pm 0.07$ & $1.04-1.35$ \\
Half squat & $1.9 \pm 0.12$ & $2.06 \pm 0.1$ & $1.79 \pm 0.1$ & $1.89 \pm 0.14$ & $1.67-2.07$ \\
Deadlift & $1.86 \pm 0.1$ & $2.06 \pm 0.08$ & $1.83 \pm 0.1$ & $1.9 \pm 0.13$ & $1.68-2.15$ \\
\hline
\end{tabular}

The mean age of Iranian male karate athletes was $23.27 \pm 2.83$ years, which was approximately equal to that of Italian karate athletes $(23.8 \pm 2.8$ years $)[20]$ but lower than those found in their Brazilian counterparts (28.0 \pm 5.1 years) [36]. The aging of athletes has been shown to decrease strength, power, and reaction time, and consequently lead to inferior performance $[41,30]$. Accordingly, it appears that older athletes tend to win using decision and strategies, and they seek to avoid situations where they are at a disadvantage [35].

One specific measurement that has been introduced is the 'ape index' - a measure of arm span to stature. Whilst the general population has an average 1:1 ratio of the ape index, athletes who possess a higher ratio appear to have the desired potential for success in some sports. It has been reported that winners showed greater stature and arm span compared to the average of all contestants participating in mixed martial arts competitions [27]. The ape index value was 1.02 for male karate athletes $(1,1.03$ and 1.02 for light, middle and heavy weight categories).

The studies comparing body structure of elite karate athletes versus non-elite karate athletes showed the supremacy of elite karate athletes in vertical physical build alongside a lower skelic index value, which indicates a lower proportion of sitting height to height and longer lower limbs [20,26].
However, despite the similarity in height among these athletes (Iran, $181.5 \mathrm{~cm}$ vs Italy, $180 \mathrm{~cm}$ and Brazil, $181.6 \mathrm{~cm}$ ), the skelic index value was higher among Iranian athletes, indicating a lower proportion of lower limbs to height compared to their Italian counterparts. During karate sparring, many diverse techniques are performed, all of which, in general, must be executed explosively with high speed (in accordance with World Karate Federation rules) [11]. Here, the athletes with long stature seem to possess a distinct advantage for gaining points before the opponent, because a greater height may facilitate reach in punches and kicks [31].

A long upper body can be an advantage in sports (e.g. wrestling and weightlifting) whose athletes require excellent strength in upper limbs [1]. Although our findings about the ratio of leg to stature were in contrast to those found in Italian karate athletes, due to struggles and physical tussles regularly occurring during kumite, a longer upper body can play a facilitatory role in throwing down the opponent to the ground and executing the techniques on him/her. Note that, the lower-located center of gravity can be accompanied by optimum execution of techniques in terms of steadiness and proficiency in such conditions. Additionally, the lower proportion of leg to stature among Iranian karate athletes compared to their European colleagues, which can be attributed to genetic influence (the 
Asian population has a higher sitting height to height ratio compared with European and African populations) [32], may be considered a determining factor for athletes in contemporary karate, which is to a large extent characterized by quick and ballistic movements. Nevertheless, Iranian karate athletes may take advantage of convenient accessibility along with quick movements simultaneously. In this research, light weight athletes showed shorter body segments. These clear-cut differences can be justified through the association of smaller body dimensions and lower body weights.

Athletes competing in martial arts are highly mesomorphic due to the importance of strength, power, speed and agility in such sport disciplines. However, they do vary in both endomorphy and ectomorphy components according to their weight classes [1]. Sterkowicz-Przybycień [39] observed that international level karate athletes were more muscular, and they also were more mesomorphic and less ectomorphic than national karate athletes.

Based on our results, elite karate athletes were balanced mesomorphs (overall). More specifically, the 3 main weight divisions were ectomorphic-mesomorph for light and middle weight categories and endomorphic-mesomorph for the heavy weight category. These findings indicate that light and middle weight elite karate athletes tend to have a higher ectomorphy rating and athletes in the heavy weight category have a tendency toward endomorphy.

Maximizing fat-free mass is favorable for athletes involved in sports which require strength, power and muscular endurance. In general, higher body weight induced by increased fat mass may often result in poor performance. Many studies have indicated that the higher the rates of body fat are, above optimal values, the weaker is the performance. This is more likely found in sports in which the body weight must be moved through space [13].

It is desirable that karate athletes possess a low body fat percentage. Nonetheless, the body fat among high-level karate athletes has been reported to vary from $7.5 \%$ for Japanese karate athletes to $16.8 \%$ for their Polish peers [11]. Some studies on body composition of elite karate athletes compared to lower-ranked karate athletes showed no significant difference in body fat percentage between the two groups of athletes. However, there are some cases of dissimilarities in lean body mass and fat distribution pattern, suggesting the preeminence of elite karate athletes $[23,20]$. The mean body fat of Iranian karate athletes was found to be $8.66 \pm 3.65 \%$, which was perceptibly lower than the values observed in Portuguese $(14.1 \pm 3.46 \%)$, French $(13.7 \pm 4.1 \%)$, Polish $(16.8 \pm 2.5 \%)$ and British $(16.5 \pm 4.6 \%)$ international karate athletes $[17,33,39,40]$. Moreover, higher percentages of body fat were found in higher weight classes.

In karate sparring, the acyclic activity profile of numerous forward, backward and side steps, and hopping movements combined with short duration high-intensity bouts of frequent techniques followed by interruptions result in a metabolic profile in which energy supply is predominantly aerobic, and anaerobic energy supplementation is available through high-energy phosphates. Accordingly, the consistency of performance is also greatly determined by the ability to sustain the intensity of activity during the match, as well as faster recovery between successive combats which are supported by aerobic power and capacity. Despite the higher levels of activity, the contribution of anaerobic metabolism rises only a little and reaches $7.4 \%$ anaerobic lactic and $17.9 \%$ anaerobic alactic. Thus, even though there are additional activities and strikes, the metabolic profile remains predominantly aerobic $[6,16]$.

Aerobic power is considered a valid indicator of respiratory, cardiovascular and muscular system cooperative function, and is one of the most important factors affecting combat sports performance $[24,2,11]$. In comparison to other sports, reported values for $\mathrm{VO}_{2 \max }$ of elite karate athletes were analogous to those of their elite counterparts in taekwondo [7, 9] and wrestling [42], but lower than those observed in boxers [38]. The value of $\mathrm{VO}_{2 \max }$ was $51.58 \pm 3.39 \mathrm{ml} \cdot \mathrm{kg}^{-1} \cdot \mathrm{min}^{-1}$, which was higher than that of Italian athletes $\left(48.5 \pm 6 \mathrm{ml} \cdot \mathrm{kg}^{-1} \cdot \mathrm{min}^{-1}\right)$ [16], but it was lower than the values reported in Japanese $\left(57.5 \pm 5.2 \mathrm{ml} \cdot \mathrm{kg}^{-1} \cdot \mathrm{min}^{-1}\right)$ [23] and French $\left(57.2 \pm 4.1 \mathrm{ml} \cdot \mathrm{kg}^{-1} \cdot \mathrm{min}^{-1}\right)$ [34] karate athletes. However, different tests were used to determine maximal oxygen consumption.

It is noteworthy that the heavy weight category showed a lower average $\mathrm{VO}_{2 \max }$ compared to the two other weight divisions. Since the average body fat percentage was higher in the heavy weight class, these differences can be partly attributed to the association of body fatness with maximal oxygen consumption. Excess amounts of body fat decrease performance in activities involving weight bearing by increasing the body weight, and therefore increase the energy requirement without contributing to the energy-producing capacity. As a result, $\mathrm{VO}_{2 \max }$ is likely elicited at a lower rate of work and the velocity that can be maintained for a certain period of time is reduced [14].

Ravier et al. [34] found a significant difference between national $\left(10.9 \pm 1.5 \mathrm{~W} \cdot \mathrm{kg}^{-1}\right)$ and international level $\left(12.5 \pm 1.3 \mathrm{~W} \cdot \mathrm{kg}^{-1}\right)$ karate players in maximal power, suggesting the ability of maximal power output to discriminate diverse level karate athletes. However, it is not the case for strength. Roschel et al. [36] reported no significant difference between winner and defeated karate athletes in squat and bench press 1RM. Nonetheless, they observed a significant difference between the two groups in power at light loads ( $30 \% 1 \mathrm{RM})$. Conversely, based on Imamura et al. [23], highly competitive black belt karate athletes showed higher 1RM in both the bench press and half squat than novice karate athletes. Karate practice consists of performing 
unloaded punches and kicks, which can cause some adaptations in the velocity portion of the force-velocity curve, and therefore results in greater segment velocity. Collectively, these results indicate that the maximal dynamic strength is not crucial to high-level karate performance, and excellent performance depends greatly on muscular power [36]. In other words, among top-level karate competitors, muscular power appears to be able to demonstrate comparative differences more sensitively.

The average bench press and squat 1RM values were higher than those observed in previous studies [23, 36]. Although increased 1RM (absolute values) in all three strength exercises were found in higher weight divisions, the middle weight category showed best relative strength values. This was also true in anaerobic power, explosive power (lower body), speed and agility, and the middle weight class showed superlative performance.

\section{Conclusion}

Our results enabled us to determine further details of the dominant characteristics of top-level karate athletes. Although some dissimilarities were found between Iranian karate athletes and their counterparts in other countries, these findings reaffirmed the main anthropometric and physiological features as the prominent traits of karate athletes who compete at international level. However, this research has limitations, because only Iranian karate athletes took part in the study. Thus, the same research on international level karate athletes from other countries, especially those who are highly ranked, appears to be required to ascertain the physical and physiological profile more precisely.

\section{Conflict of interest: Authors state no conflict of interest.}

\section{References}

1. Ackland T.R., B. Elliott, J. Bloomfield (2009) Applied anatomy and biomechanics in sport. Hum. Kinet., pp. 98.

2. Andreato L.V., S.F. de Moraes, T.L. de Moraes Gomes, J.D.C. Esteves, T.V. Andreato, E. Franchini (2011) Estimated aerobic power, muscular strength and flexibility in elite Brazilian Jiu-Jitsu athletes. Sci. Sports, 26(6): 329-337. DOI: 10.1016/j.scispo.2010.12.015.

3. Baker J.S., W. Bell (1990) Energy-expenditure during simulated karate competition. J. Hum. Mov. Stud., 19(2): 69-74.

4. Baumgartner T.A., A.S. Jackson, M.T. Mahar, D.A. Rowe (2015) Measurement for evaluation in kinesiology. Jones \& Bartlett Publishers, pp. 268.
5. Beekley M.D., T. Abe, M. Kondo, T. Midorikawa, T. Yamauchi (2006) Comparison of normalized maximum aerobic capacity and body composition of sumo wrestlers to athletes in combat and other sports. J. Sports Sci. Med., 5(CSSI): 13-20.

6. Beneke R., T. Beyer, C. Jachner, J. Erasmus, M. Hütler (2004) Energetics of karate kumite. Eur. J. Appl. Physiol., 92(4-5): 518-523. DOI: 10.1007/s00421-004-1073-x.

7. Bouhlel E., A. Jouini, N. Gmada, A. Nefzi, K.B. Abdallah, Z. Tabka (2006) Heart rate and blood lactate responses during Taekwondo training and competition. Sci. Sports, 21(5): 285-290. DOI: 10.1016/j.scispo.2006.08.003.

8. Brzycki M. (1993) Strength testing - predicting a one-rep max from reps-to-fatigue. J. Phys. Educ. Recreat. Dance, 64(1): 88-90. DOI: 10.1080/07303084.1993.10606684.

9. Butios S., N. Tasika (2007) Changes in heart rate and blood lactate concentration as intensity parameters during simulated Taekwondo competition. J. Sports Med. Phys. Fit., 47(2): 179-185.

10. Carter J.E.L. (2002) The Heath-Carter anthropometric somatotype. Instruction manual. San Diego: USA Department of Exercise and Nutritional Sciences.

11. Chaabène H., Y. Hachana, E. Franchini, B. Mkaouer, K. Chamari (2012) Physical and physiological profile of elite karate athletes. Sports Med., 42(10): 829-843. DOI: 10.1007/BF03262297.

12. Chaabene H., E. Franchini, S. Sterkowicz, M. Tabben, Y. Hachana, K. Chamari (2015) Physiological responses to karate specific activities. Sci. Sports, 30(4): 179-187. DOI: 10.1016/j.scispo.2015.03.002.

13. Costill D.L., J.H. Wilmore, W.L. Kenney (2008) Physiology of sport and exercise. Hum. Kinet., pp. 361.

14. Cureton K.J., P.B. Sparling (1980) Distance running performance and metabolic responses to running in men and women with excess weight experimentally equated. Med. Sci. Sports Exerc., 12(4): 288-294.

15. De Lorenzo A., I. Bertini, L.I.E. Pagliato (2000) Body composition measurement in highly trained male athletes: a comparison of three methods. J. Sports Med. Phys. Fit., 40(2): 178-183.

16. Doria C., A. Veicsteinas, E. Limonta, M.A. Maggioni, P. Aschieri, F. Eusebi, G. Fano, T. Pietrangelo (2009) Energetics of karate (kata and kumite techniques) in toplevel athletes. Eur. J. Appl. Physiol., 107(5): 603. DOI: 10.1007/s00421-009-1154-y.

17. Ferreir M.A.R., A.V. Brito (2010) Electromechanical delay in ballistic movement of superior limb: comparison between karate athletes and nonathletes. Percept. Motor Skills, 111(3): 722-734.

18. Franchini E., M.Y. Takito, M.A.P.D.M. Kiss, S. Strerkowicz (2005) Physical fitness and anthropometrical differences between elite and non-elite judo players. Biol. Sport, 22(4): 315-328. 
19. Fritzsche J., C. Raschka (2007) Sports anthropological investigations on somatotypology of elite karateka. Anthropologischer Anzeiger; Bericht uber die biologischanthropologische Literatur, 65(3): 317-329.

20. Giampietro M., A. Pujia, I. Bertini (2003) Anthropometric features and body composition of young athletes practicing karate at a high and medium competitive level. Acta Diabetol., 40(1): 145-148. DOI: 10.1007/s00592003-0049-3.

21. Gualdi-Russo E., I. Graziani (1993) Anthropometric somatotype of Italian sport participants. J. Sports Med. Phys. Fit., 33(3): 282-291.

22. Iide K., H. Imamura, Y. Yoshimura, A. Yamashita, K. Miyahara, N. Miyamoto, C. Moriwaki (2008) Physiological responses of simulated karate sparring matches in young men and boys. J. Strength Cond. Res., 22(3): 839-844. DOI: 10.1519/JSC.0b013e31816a5af6.

23. Imamura H., Y. Yoshimura, K. Uchida, S. Nishimura, A.T. Nakazawa (1998) Maximal oxygen uptake, body composition and strength of highly competitive and novice karate practitioners. Appl. Hum. Sci., 17(5): 215-218. DOI: 10.2114/jpa.17.215.

24. Impellizzeri F.M., S.M. Marcora (2007) The physiology of mountain biking. Sports Med., 37(1): 59-71. DOI: 10.2165/00007256-200737010-00005.

25. Jackson A.S., M.L. Pollock (1978) Generalized equations for predicting body density of men. Br. J. Nutr., 40(03): 497-504.

26. Katić R., S. Blažević, S. Krstulović, R. Mulić (2005) Morphological structures of elite karateka and their impact on technical and fighting efficiency. Coll. Antropol., 29(1): 79-84.

27. Kirk C. (2016) the influence of age and anthropometric variables on winning and losing in professional mixed martial arts. Facta Univ., Series: Phys. Educ. Sport, 14(2): 227-236.

28. Macan J., D. Bundalo-Vrbanac, G. Romić (2006) Effects of the new karate rules on the incidence and distribution of injuries. Br. J. Sports Med., 40(4): 326-330. DOI: 10.1136/bjsm.2005.022459.

29. Marfell-Jones M., T. Olds, A. Stewart, L. Carter (2006) International Standards for Anthropometric Assessment. Potchesfstroom: International Society for the Advancement of Kinanthropometry.

30. Nessel, E.H. (2004) The physiology of aging as it relates to sports. J. Am. Med. Athletic Assoc., 17(2): 12-18.

31. Noorul H.R., W. Pieter, Z.Z. Erie (2008) Physical fitness of recreational adolescent taekwondo athletes. Brazilian J. Biomotr., 2(4): 230-240.

32. Norton K., T. Olds (1996) Anthropometrica: a textbook of body measurement for sports and health courses. UNSW press, pp. 231.

33. Ravier G., B. Dugue, F. Grappe, J.D. Rouillon (2006) Maximal accumulated oxygen deficit and blood responses of ammonia, lactate and $\mathrm{pH}$ after anaerobic test: a comparison between international and national elite karate athletes. Int. J. Sports Med., 27(10): 810-817. DOI: 10.1055/s-2005-872965.

34. Ravier G., F. Grappe, J.D. Rouillon (2004) Application of force-velocity cycle ergometer test and vertical jump tests in the functional assessment of karate competitor. J. Sports Med. Phys. Fit., 44(4): 349-355.

35. Rittweger J., A. Kwiet, D. Felsenberg (2004) Physical performance in aging elite athletes-Challenging the limits of Physiology. J. Musculoskelet. Neuronal Interact., 4(2): 159-160.

36. Roschel H., M. Batista, R. Monteiro, R.C. Bertuzzi, R. Barroso, I. Loturco, C. Ugrinowitsch, V. Tricoli, E. Franchini (2009) Association between neuromuscular tests and kumite performance on the Brazilian Karate National Team. J. Sports Sci. Med., 8(Special Issue 3): 20-24.

37. Siri W.E. (1956) The gross composition of the body. Adv. Biol. Med. Phys., 4: 239-280.

38. Smith M.S. (2006) Physiological profile of senior and junior England international amateur boxers. J. Sports Sci. Med., 5(CSSI): 74-89.

39. Sterkowicz-Przybycień K.L. (2010) Body composition and somatotype of the top of polish male karate contestants. Biol. Sport, 27(3): 195-201.

40. Baker J.S., B. Davies (2006) Variation in resistive force selection during brief high intensity cycle ergometry: implications for power assessment and production in elite karate practitioners. J. Sports Sci. Med., 5: 42-46.

41. Vingren J.L., W.J. Kraemer, N.A. Ratamess, J.M. Anderson, J.S. Volek, C.M. Maresh (2010) Testosterone physiology in resistance exercise and training. Sports Med., 40(12): 1037-1053. DOI: 10.2165/11536910-00000000000000 .

42. Yoon J. (2002) Physiological profiles of elite senior wrestlers. Sports Med., 32(4): 225-233. DOI: 10.2165/00007256-200232040-00002.

43. Zehr E.P., D.G. Sale, J.J. Dowling (1997) Ballistic movement performance in karate athletes. Med. Sci. Sports Exerc., 29(10): 1366-1373. DOI: 10.1097/00005768199710000-00014.

\section{Received 17.04.2017 \\ Accepted 17.07.2017}

(C) University of Physical Education, Warsaw, Poland

\section{Acknowledgments}

We would like to acknowledge the I.R. Iran Karate Federation and all the Iranian national karate athletes who participated in this study. 